\title{
An Update on Techniques of Photocoagulation Treatment of Proliferative Sickle Cell Retinopathy
}

\author{
LEE M. JAMPOL, MARILYN FARBER, MAURICE F. RABB, GRAHAM SERJEANT \\ Illinois USA and Kingston, Jamaica
}

\begin{abstract}
Summary
Proliferative sickle cell retinopathy (PSR) can lead to visual loss from vitreous haemorrhage and traction or rhegmatogenous retinal detachment. We review two techniques of photocoagulation for PSR, feeder vessel photocoagulation and scatter photocoagulation. A prospective randomised trial of feeder vessel photocoagulation for PSR demonstrated that the incidence of vitreous haemorrhage and visual loss was diminished in eyes which were treated. Since this technique of treatment is difficult and can be associated with choroidal neovascularisation and retinal tears, scatter photocoagulation has also been tested. A prospective randomised trial of scatter photocoagulation for PSR demonstrated a decreased incidence of vitreous haemorrhage and visual loss in treated eyes compared to untreated eyes. No complications of scatter treatment were noted.

We presently recommend local scatter photocoagulation to areas of PSR. In unreliable patients, we recommend 360 degrees of peripheral circumferential treatment as otherwise new seafans will develop. If scatter photocoagulation does not result in sufficient regression of the neovascularisation and vision threatening complications such as vitreous haemorrhage continue, feeder vessel treatment can be used to supplement the scatter treatment.
\end{abstract}

The major causes of visual loss in patients with sickle cell disease are vitreous haemorrhage, traction retinal detachment and epiretinal membrane formation. ${ }^{1}$ Other causes are rhegmatogenous retinal detachment, exudative retinal detachment, macular ischaemia, arterial occlusions, macular hole formation and angioid streaks with macular degeneration. In an attempt to prevent visual loss from vitreous haemorrhage, traction retinal detachment, exudative retinal detachment and rhegmatogenous retinal detachment, photocoagulation has been used to close the seafan lesions of proliferative sickle cell retinopathy (PSR). Over the last 13 years, we have performed two major randomised clinical trials investigating the role of photocoagulation in treating patients with proliferative sickle cell disease. This paper summarises the techniques and results of treatment.

\section{Methods and Materials}

Prospective randomised clinical trials ${ }^{2-5}$ involving patients with PSR were performed in

From: Departments of Ophthalmology, Northwestern University Medical School and the University of Illinois College of Medicine, Chicago, Illinois and the Medical Research Council Laboratory, Kingston, Jamaica.

Supported in part by PHS Grant \#HL15168 from the National Heart, Lung, and Blood Institute, National Institutes of Health, Bethesda, Maryland and by an unrestricted grant from Research to Prevent Blindness, Inc., New York City.

Correspondence to: Lee M. Jampol, MD, 303 E. Chicago Avenue, Chicago, IL 60611. 
Kingston, Jamaica and Chicago, Illinois. Patients with haemoglobin SC, SS, or S betathalassaemia were included in the trials. In each of the two trials, patients with eligible bilateral proliferative retinopathy, after informed consent, had one eye assigned to photocoagulation treatment and the other eye remained untreated and served as a control. Patients with eligible unilateral proliferative retinopathy had that eye allocated to either treatment or control. In these trials, photocoagulation was performed using Xenon arc photocoagulation (Kingston portion of the feeder vessel trial $)^{2,3}$ or blue/green argon laser photocoagulation (the scatter laser treatment study in Kingston ${ }^{5}$ and the feeder vessel trial in Chicago $)^{2,4}$ Data were collected in each centre and the outcomes of eyes assigned to treatment and control groups were compared.

\section{Feeder Vessel Photocoagulation ${ }^{2-4}$}

In Kingston, Jamaica, feeder vessel photocoagulation was performed following a retrobulbar anaesthetic with the application of photocoagulation burns using the O'Malley Log II Xenon arc photocoagulator. Intense spots were placed on the feeding arterioles and the draining venules from each neovascular lesion. If subsequent fluorescein angiography demonstrated that the neovascular lesion was still perfused, additional treatment was applied. An attempt was made to close all proliferative lesions in each treated eye.

In the feeder vessel study in Chicago, the Coherent Model 800 blue-green argon laser was used. Intense treatment spots were placed on the feeder arteriole and, after segmentation of that vessel, the draining venule. In general, spot sizes were 500 microns, 0.2 seconds duration and with a power setting high enough to allow closure of the feeding arteriole. If the arteriolar blood column could not be segmented, then additional treatment was often performed several weeks later when thinning and pigmentation had occurred in the area of treatment. ${ }^{6}$ At this time, with retreatment on the same spots, easier closure of the feeding arterioles was possible. Draining venules were closed when the arteriole had been successfully segmented. Again, an attempt was made to close all neovascular lesions in treated eyes. If additional seafan neovascular lesions developed in treated eyes, they were similarly treated.

\section{Scatter Photocoagulation 5}

Patients with PSR were treated in Kingston with a localised scatter technique using the Britt Model 3250 argon blue/green laser. Grey-white $500 \mu$ spots were placed in the vicinity of the proliferative lesions. Burns were approximately one burn diameter apart and extended from one disc diameter posterior to the lesion to one disc diameter anterior to the lesion and one clock hour to each side. Enough spots were placed to completely surround the neovascular lesion, but no attempt was made directly to treat the seafan or the feeding vessels. If the lesion subsequently remained perfused and skip areas were seen, additional treatment was often applied. If new neovascular lesions developed in a treated eye, they were similarly treated. Ophthalmic examination with fluorescein angiograms was used to determine whether neovascular lesions were larger, nonperfused, partly regressed, or unchanged.

\section{Results}

The feeder vessel photocoagulation study provided important treatment guidelines for using this technique in patients with PSR. ${ }^{2-4}$ An analysis of the untreated eyes in that study showed that there were three risk factors for the development of vitreous haemorrhage: ${ }^{3}$

(1) The presence of haemoglobin SC (as opposed to SS or SB thalassaemia).

(2) Any vitreous haemorrhage in the eye at the time the patient was first seen.

(3) Greater than 60 cumulative degrees of perfused neovascularisation.

This study also showed that both xenon arc photocoagulation and argon laser photocoagulation were effective in preventing the occurrence of vitreous haemorrhage. In addition, with the data from the two centers (Kingston and Chicago) combined, photocoagulation was effective in reducing visual loss from vitreous haemorrhage and the occurrence of visual loss from any cause. It was concluded that feeder vessel photocoagulation was an effective technique for preventing vitreous haemorrhage and visual loss from sickle cell disease. 
A long-term follow-up of the Chicago patients from this study has recently been reported. ${ }^{4}$ Of the 44 patients originally enrolled, nearly a decade of follow-up was achieved in 22 patients. There were 15 control, untreated, eyes and 20 argon laser treated eyes. Prolonged loss of visual acuity was rare in both groups. Argon laser photocoagulation had a sustained effect reducing the incidence of vitreous haemorrhage and visual loss. Eight of 15 control eyes $(53 \%)$ had vitreous haemorrhage and it recurred at least once in five of these eight eyes $(63 \%)$. Only a single episode of vitreous haemorrhage was observed in one treated eye. Spontaneous autoinfarction of seafans was seen in four of 15 control eyes and was complete in three of these. The argon laser complications, choroidal neovascularisation ${ }^{7,8}$ or retinal tears and detachment $^{9}$ were not associated with longterm visual loss. More than half of both the treated and control eyes developed new seafans.

Several factors have made feeder vessel photocoagulation a less than ideal treatment. Most retinal specialists and the vast majority of ophthalmologists`are not familiar with the technique of feeder vessel treatment and the placement of the very intense burns requires considerable skill and experience. When these intense burns are placed, it is possible to break Bruch's membrane and cause choroidal haemorrhage or the ingrowth of choroidal neovascularisation, which is commonly seen, especially after xenon arc photocoagulation..$^{2-4,6-8}$ This can sometimes lead to further vitreous haemorrhage and visual loss, although this is rare. ${ }^{4,7,8}$ In addition, we have demonstrated that with feeder vessel argon laser treatment, the progression of vitreous traction is often associated with the development of retinal tears in the area of treatment. ${ }^{9}$ Because of these problems, a scatter technique of treatment was devised. ${ }^{10-12}$ This treatment has been shown to be effective for retinal neovascularisation from diabetes mellitus and branch retinal vein occlusion as well as in other situations.

Prior studies suggested that scatter treatment was effective for patients with PSR. $\operatorname{Redman}^{10}$ in 1982 reported on local scatter treatment in 21 eyes with 45 seafans. There was complete or partial regression in $77.8 \%$ of the seafans. Cruess and coworkers ${ }^{11}$ have reported on their technique of 360 degree peripheral circumferential scatter treatment in 40 eyes. They noticed complete or partial regression in $83 \%$ of eyes and in a second paper reporting 70 eyes, they noticed complete regression in $33 \%$ of the seafans and partial regression of $46 \%$. Only $2 \%$ progressed. Again, there were no apparent complications from the treatment. Only one eye developed new seafans.

New data are now available from our randomised trial on the effectiveness of scatter treatment. ${ }^{5}$ In 174 eyes (with a mean follow-up of 42 months in control eyes and 47 months in the treated eyes), complete closure of the neovascularisation occurred in $30.2 \%$ of the 99 laser treated eyes and partial closure in $51 \%$. New seafans developed in $34.3 \%$ of these eyes. In comparison, in control eyes ( 75 eyes), autoinfarction occurred in $22.4 \%$ of eyes and partial autoinfarction in $23.7 \%$; new seafans developed in $41.3 \%$ of the eyes. Scatter treatment was effective in reducing visual loss from $8.3 \%$ (control) to $3 \%$ (treated), $\mathrm{p}=.019$. It was also effective in reducing visual loss from vitreous haemorrhage, $1 \%$ (treated) vs. $6.7 \%,($ control $)(p=.032)$ and the occurrence of any vitreous haemorrhage was also reduced in the treated eyes when the data were corrected for known risk factors at entry. Although visual loss occurred in both groups from vitreous haemorrhage, epiretinal membrane formation and other mechanisms, no apparent deleterious effects of laser treatment were seen.

The technique of scatter treatment that we have used involves only a local scatter. It is possible that $360^{\circ}$ degrees of treatment would be more effective in preventing the development of new neovascularisation, which we saw in $34.3 \%$ of the treatment eyes. We suspect that a randomised clinical trial comparing local scatter to 360 degree scatter would not demonstrate a difference in the outcome between the two groups since both techniques are highly effective and apparently have few side effects.

Based upon these clinical trials, our recommendations for the therapy of PSR are as follows: 
When PSR is detected, scatter treatment should be instituted. If a patient is reliable and can return for follow-up examinations on a regular basis, then a local scatter treatment should result in regression of the present neovascular lesions. Later, if new neovascular lesions develop, then additional scatter treatment is performed. If the patient is unreliable for follow-up, then a 360 degree technique of scatter treatment should be considered. We do not feel, at present, that all eyes with PSR should be treated with a 360 degree scatter as it is possible that this more extensive treatment might facilitate the development of macular pucker and vitreous traction, important factors in visual loss in these patients. Since regression can usually be obtained with local scatter, and since the seafans that later form, if detected early, can be easily treated, we have not instituted 360 degree scatter in most patients.

In the event that the scatter treatment produces no regression or partial regression of a lesion and the patient continues to have problems, for example, repeated vitreous haemorrhage or progressive traction, then a feeder vessel technique of treatment should be considered. This therapy should then be applied directly to the feeding arterioles and draining venules from the still perfused neovascular lesions. The presence of the scatter treatment around the neovascular lesion may be helpful in preventing retinal tears and detachment, noted previously as a complication of the argon laser feeder vessel technique. ${ }^{9}$

Key words: sea fan, proliferative sickle cell retinopathy, laser, xenon arc, scatter photocoagulation, feeder vessel photocoagulation.

\footnotetext{
References

${ }^{1}$ Moriarty BJ, Acheson RW, Condon PI, Serjeant
}

GR: Patterns of visual loss in untreated sickle cell retinopathy. Eye 1988. 2: 330-5.

${ }^{2}$ Jampol LM, Condon P, Farber M, Rabb M, Ford S, Serjeant G: A randomised clinical trial of feeder vessel photocoagulation of proliferative sickle cell retinopathy: I Preliminary results. Ophthalmology 1984. 90: 450-5.

${ }^{3}$ Condon P, Jampol LM, Farber MD, Rabb M, Serjeant G: A randomised clinical trial of feeder vessel photocoagulation of proliferative sickle cell retinopathy: II Update and analysis of risk factors. Ophthalmology 1984, 91: 1496-8.

${ }^{4}$ Jacobson MS, Gagliano DA, Cohen SB, Rabb MF, Jampol LM, Farber MD, Goldberg MF: A randomised clinical trial of feeder vessel photocoagulation of sickle cell retinopathy: A long-term follow-up Ophthalmology (In press).

${ }^{5}$ Farber MD, Jampol LM, Fox P, Moriarty BJ, Acheson RW, Rabb MF, Serjeant GR: A randomised clinical trial of scatter photocoagulation of proliferative sickle cell retinopathy. Arch Ophthalmol (In Press).

publication).

${ }^{6}$ Goldberg MF and Jampol LM. Treatment of neovascularization, vitreous haemorrhage, and retinal detachment in sickle cell retinopathy. In Symposium on Medical and Surgical Diseases of the Retina and Vitreous. St. Louis CV Mosby 1983; 53-81.

${ }^{7}$ Dizon-Moore RV,. Jampol LM, Goldberg MF: Chorioretinal and choriovitreal neovascularization: Their presence after photocoagulation of proliferative sickle retinopathy. Arch Ophthalmol 1981. 99: 842-9.

${ }^{8}$ Carney MD, Paylor RR, Cunha-Vaz JG, Jampol LM, Goldberg MF: Iatrogenic choroidal neovascularization in sickle cell retinopathy. Ophthalmology 1986. 93: 1163-8.

${ }^{9}$ Jampol LM and Goldberg MF: Retinal breaks after photocoagulation of proliferative sickle cell retinopathy. Arch Ophthalmol 1980. 98: 676-9.

${ }^{10}$ Rednam KRV, Jampol LM, Goldberg MF: Scatter retinal photocoagulation for proliferative sickle cell retinopathy. Am J Ophthalmol 1982. 93: 594-9.

${ }^{11}$ Cruess AF, Stephens RF, Magargal LE, Brown GC: Peripheral circumferential retinal scatter photocoagulation for treatment of proliferative sickle retinopathy. Ophthalmology 1983 90: 272-8.

${ }^{12}$ Kimmel AS, Magargal LE, Stephens RF, Cruess AF: Peripheral circumferential retinal scatter photocoagulation for the treatment of proliferative sickle retinopathy. An update. Ophthalmology 1986. 93: 1429-34. 